\title{
A systemic administration of liposomal curcumin inhibits radiation pneumonitis and sensitizes lung carcinoma to radiation
}

This article was published in the following Dove Press journal:

International Journal of Nanomedicine

23 May 2012

Number of times this article has been viewed

\author{
Hua-shan Shi ${ }^{1}, *$ \\ Xiang Gao ${ }^{1,3, *}$ \\ Dan $\mathrm{Li}^{1}$,* \\ Qiong-wen Zhang' \\ Yong-sheng Wang ${ }^{2}$ \\ Yu Zheng' \\ Lu-Lu Cai' \\ Ren-ming Zhong ${ }^{2}$ \\ Ao Rui' \\ Zhi-yong Li' \\ Hao Zheng' \\ Xian-cheng Chen' \\ Li-juan Chen'
}

'State Key Laboratory of Biotherapy and Cancer Center, West China Hospital, West China Medicine

School, Sichuan University, Chengdu, Sichuan, People's Republic of China;

${ }^{2}$ State Key Laboratory of Biotherapy and Department of Thoracic

Oncology, West China Hospital, West China Medical School, Sichuan University, Chengdu, Sichuan, People's Republic of China; ${ }^{3}$ Deparment of Pathophysiology, College of Preclinical and Forensic Medical Sciences,

Sichuan University, Chengdu, People's Republic of China

*These authors contributed equally to this work

Correspondence: Yong-sheng Wang State Key Laboratory of Biotherapy and Department of Thoracic Oncology,

West China Hospital, West China Medical

School, Sichuan University, Keyuan Road 4,

Chengdu, Sichuan 61004I,

People's Republic of China

Tel +862885164059

Fax +86 28 85I64060

Email wangys@scu.edu.cn

\begin{abstract}
Radiation pneumonitis (RP) is an important dose-limiting toxicity during thoracic radiotherapy. Previous investigations have shown that curcumin is used for the treatment of inflammatory conditions and cancer, suggesting that curcumin may prevent RP and sensitize cancer cells to irradiation. However, the clinical advancement of curcumin is limited by its poor water solubility and low bioavailability after oral administration. Here, a water-soluble liposomal curcumin system was developed to investigate its prevention and sensitizing effects by an intravenous administration manner in mice models. The results showed that liposomal curcumin inhibited nuclear factor- $\kappa \mathrm{B}$ pathway and downregulated inflammatory factors including tumor necrosis factor- $\alpha$, interleukin (IL)-6, IL-8, and transforming growth factor- $\beta$ induced by thoracic irradiation. Furthermore, the combined treatment with liposomal curcumin and radiotherapy increased intratumoral apoptosis and microvessel responses to irradiation in vivo. The significantly enhanced inhibition of tumor growth also was observed in a murine lung carcinoma (LL/2) model. There were no obvious toxicities observed in mice. The current results indicate that liposomal curcumin can effectively mitigate RP, reduce the fibrosis of lung, and sensitize $\mathrm{LL} / 2$ cells to irradiation. This study also suggests that the systemic administration of liposomal curcumin is safe and deserves to be investigated for further clinical application.
\end{abstract}

Keywords: liposomes, curcumin, lung cancer

\section{Introduction}

Radiotherapy is one of the most important treatment modalities for many thoracic malignancies including lung cancer, breast cancer, lymphoma, thymoma, and esophageal cancer. However, radiotherapy-induced lung toxicity frequently affects the outcome of radiotherapy. Radiation pneumonitis (RP), which represents the acute phase of radiation-induced lung injury, is the major dose-limiting toxicity in radiotherapy for thoracic radiation. Despite recent improvements having been made on the delivery of radiotherapy, such as intensity-modulated radiotherapy and image-guided radiotherapy, clinically significant RP still develops in 13\%-37\% of patients receiving radical dose radiation therapy. ${ }^{1} \mathrm{RP}$-inducing acute clinical symptoms, mainly respiratory systemic symptoms, frequently result in radiotherapy failure. About $10 \%-15 \%$ patients develop severe lung toxicity after thoracic radiation. ${ }^{2}$ This is a significant problem and is contributory to noncancer-related deaths in patients receiving radiotherapy. ${ }^{3,4}$ Another consequence of RP is lung fibrosis, which leads to shortness of breath, diminished quality of life, and reduced activities of daily living accordingly.

At the molecular level, RP is believed to be a consequence of a cascade of cytokine production. ${ }^{5}$ Nuclear factor $(\mathrm{NF})-\kappa \mathrm{B}$, a transcription factor, plays a central role in the 
induction of cytokine expression in inflammatory response including the radiation-induced cascade of inflammatory responses and the further activation. Thus, inhibition of $\mathrm{NF}-\kappa \mathrm{B}$ is radioprotective for the lung and may be a synergetic strategy for cancer therapy. ${ }^{6-8}$

Curcumin, a NF- $\mathrm{KB}$ inhibitor, is used for the treatment of inflammatory conditions and cancer, and can sensitize tumors to radiation including colorectal cancer, prostate cancer, and some squamous cell carcinoma. ${ }^{9-13}$ Accumulating evidence also suggests that curcumin may be an ideal radioprotector for radiotherapy-induced lung injury. First, as a natural antioxidant, curcumin can capture and remove the free radicals caused by damage, and enhance the activity of superoxide dismutase. ${ }^{14}$ Second, curcumin exerts multiple anti-inflammatory effects through the inhibition of the NF- $\kappa \mathrm{B}$ pathway and decreases the release of inflammatory factors including monocyte chemotactic protein (MCP)-1, interleukin (IL)-1, and tumor necrosis factor (TNF)- $\alpha,{ }^{10,15-18}$ Third, curcumin is believed to be a promising medicine for inhibiting, even correcting fibrosis. ${ }^{19,20}$ Therefore, curcumin is an ideal drug for preventing and treating RP, retarding fibrosis, and sensitizing radiotherapy. However, the clinical advancement of curcumin has been limited by its poor water solubility, short biological half-life, and low bioavailability after oral administration. ${ }^{21-23}$ Development of intravenous administration with curcumin is a promising approach to resolve these issues for further application. ${ }^{24}$

\section{Materials and methods}

\section{Animals and cell lines}

C57BL/6J mice were purchased from the West China Experimental Animal Center. Murine Lewis lung carcinoma cell line LL/2 and macrophage cell line RAW264.7 was purchased from American Type Culture Collection (Manassas, VA). Both cell lines were cultured in Dulbecco's modified Eagle's medium (Invitrogen, Carlsbad, CA), each supplemented with $10 \%$ (vol/vol) fetal bovine serum (Invitrogen).

\section{Preparation of curcumin-loaded liposomes (Lipo-cur) and empty liposomes}

Lipo-cur were prepared by thin film method. Briefly, 18:1:1 lecithin/cholesterol/curcumin (weight ratio) were dissolved in ethanol and evaporated to dryness under reduced pressure in a rotary evaporator. The dried lipid film was hydrated with phosphate-buffered solution (PBS) for 1 hour at $55^{\circ} \mathrm{C}$. Then, the lipid suspension was extruded through $0.4 \mu \mathrm{m}$ and $0.1 \mu \mathrm{m}$ pore size polycarbonate membranes on a nitrogen-driven Lipex lipid extruder (Northern Lipids Inc, Burnaby, BC, Canada). The empty liposomes were prepared as described above without addition of curcumin. The liposomes were prepared in triplicate.

\section{Characterization of Lipo-cur}

Particle size and zeta potential of the Lipo-cur were determined by Malvern Nano-ZS 90 (Malvern Instruments, Worcestershire, UK). A transmission electron microscope (H-6009IV, Hitachi, Japan) was used to observe the morphology of the Lipo-cur. The liposome dispersions were diluted five times with ultrapure water, dropped on copper grids with films and negatively stained with $2 \%(\mathrm{w} / \mathrm{v})$ phosphotungstic acid, and dried at room temperature. Drug loading (DL) and encapsulation efficiency (EE) of Lipo-cur were determined as follows. Briefly, $10 \mathrm{mg}$ of the lyophilized Lipo-cur was dissolved in $0.1 \mathrm{~mL}$ chloroform and then diluted with methanol. The amount of curcumin was determined by high performance liquid chromatography (HPLC, Waters Alliance 2695, Waters, Milford, MA). Solvent delivery system was equipped with a column heater and a plus autosampler. Detection was carried out on a Waters 2996 detector. Chromatographic separations were performed on a reversed-phase C18 column (4.6 mm $\times 150 \mathrm{~mm}, 5 \mu \mathrm{m}$, Sunfire Analysis column), with the column temperature kept at $28^{\circ} \mathrm{C}$. Methanol- $0.3 \%$ acetic acid $(80 / 20, v / v)$ was used as eluent at a flow rate of $1 \mathrm{~mL}$ $\min ^{-1}$. Finally, the DL and EE of Lipo-cur were calculated according to the following equations:

$$
\begin{gathered}
\mathrm{DL}=\frac{\mathrm{Mc}}{\mathrm{Ml}+\mathrm{Mc}} \times 100 \% \\
\mathrm{EE}=\frac{\mathrm{Mc}}{\mathrm{M}} \times 100 \%
\end{gathered}
$$

where $\mathrm{Mc}, \mathrm{Ml}$, and $\mathrm{M}$ stand for the amount of encapsulated curcumin, the amount of lipids, and the amount of total curcumin used, respectively. All the experiments were performed in triplicate.

\section{In-vivo toxicity of Lipo-cur}

Lipo-cur $(10 \mathrm{mg} / \mathrm{kg})$ and normal saline (NS) were injected into $\mathrm{C} 57 \mathrm{BL} / 6 \mathrm{~J}$ mice through the tail vein. The injections were continued for 7 days. The weight of mice was observed before the treatment and after 180 days; the survival of mice was also observed. Then the mice were sacrificed to obtain the liver, kidney, lung, spleen, brain, and heart for histopathological analysis. 


\section{Mice models and treatments}

For the RP model, C57BL/6J mice were randomly assigned to receive hemi-lung radiation at a modified dose of $14 \mathrm{~Gy}$ as described previously. ${ }^{25}$ The hemi-lung radiation was performed by placing pentobarbital-anesthetized mice individually in a plastic restrainer inside a 1.5 inch thick cerrobend shield that had a window $(3.0 \mathrm{~cm} \times 1.5 \mathrm{~cm})$ exposing the right thoracic region to the radiation source.

Mice were kept at room temperature during radiation. The shield reduced the radiation dose to protected tissues by greater than $95 \%$. Lipo-cur $(5 \mathrm{mg} / \mathrm{kg}$ ) and empty liposome was injected into each of the two groups of C57BL/6J mice through the tail vein on the second day after the RP model was established. The injections were continued for 7 days. Mice were sacrificed to obtain the blood plasma at 1, 2, 3, 4, 5 , and 6 weeks after radiation. In addition, the experiments were repeated; three mice per group were sacrificed to harvest lungs for histological analysis.

For the LL/2 Lewis lung carcinoma model, $5 \times 10^{5}$ LL/2 Lewis lung carcinoma cells were subcutaneously injected in a total volume of $50 \mu \mathrm{L}$ into the right leg of C57BL $/ 6 \mathrm{~J}$ mice ( $\mathrm{n}=6$ per group). One group was treated with Lipo-cur by intravenous injection once a day for 2 weeks; one group was treated with radiation therapy once every 3 days with 5 Gy 5 times (total dose $=25$ Gy), one group was treated with the two modalities. One group was treated with empty liposome as a control. Tumors were measured. Tumor volume was calculated according to the formula: volume $=$ width $^{2} \times$ length $\times 0.52$.

\section{Detection of chemokine production by enzyme-linked immunosorbent assay (ELISA)}

IL-6, IL-8, IL-10, TNF- $\alpha$, and transforming growth factor (TGF)- $\beta$ cytokine concentration were measured by ELISA and expressed as $\mathrm{pg} / \mathrm{mL}$ in plasma. Thawed plasma $(200 \mu \mathrm{L})$ was used in the ELISA according to the manufacturer's instructions. Optical absorbance was determined using an EXL-800 microplate reader.

\section{Chemotaxis and chemokinesis assays}

Murine macrophage-like (RAW264.7) cells were used to assess the effects of Lipo-cur to inhibit the activity of NF- $\kappa B$. Migration of macrophage cell lines across a $10 \mathrm{pm}$ thick Nucleopore $^{\circledR}$ (Whatman plc, Maidstone, Kent, UK) polycarbonate filter containing $5 \mathrm{pm}$ holes was measured in a 24-well chemotaxis chamber. The top wells contained 50,000 cells in minimum essential medium with $10 \%$ heat-inactivated fetal calf serum, and the bottom wells contained a 1:100 dilution of endotoxin-activated mouse serum in Roswell Park Memorial Institute 1640 medium. The cells were then incubated for 4 hours at $37^{\circ} \mathrm{C}$ in an atmosphere of $5 \% \mathrm{CO}_{2}, 95 \%$ air.

Migrated cells were counted. AS605240 was used as a positive control as described previously. ${ }^{26}$ In most experiments, less than $1 \%$ of the input cells migrated in the absence of attractant.

\section{Electrophoretic mobility shift assays (EMSA)}

NF- $\kappa \mathrm{B}$ activation was analyzed by EMSA as follow. EMSA were performed by incubating $2.5 \mu \mathrm{g}$ of nuclear extract in 12 $\mu \mathrm{L}$ of binding buffer $[5 \mathrm{mmol} / \mathrm{L}$ HEPES (4-(2-hydroxyethyl)1-piperazineethanesulfonic acid), $\mathrm{pH} 7.9,5 \mathrm{mmol} / \mathrm{L} \mathrm{MgCl}$, $50 \mathrm{mmol} / \mathrm{L} \mathrm{KCl}, 0.5 \mathrm{mmol} / \mathrm{L}$ dithiothreitol, $0.4 \mathrm{mg} / \mathrm{mL}$ poly (dI-dC) (Pharmacia Biotech, Piscataway, NJ), $0.1 \mathrm{mg} / \mathrm{mL}$ sonicated double-stranded salmon sperm DNA, and 10\% glycerol] for 10 minutes at room temperature. 32P endlabeled 45-mer double-stranded NF- $\mathrm{KB}$ oligonucleotide from HIV-I long-terminal (5'-TTGTTACAAGGGACTTTCCGCTGGGGACTTTCCAGG- GAGG CGTGG-3') was added and incubated for 30 minutes at $37^{\circ} \mathrm{C}$, and the DNAprotein complex resolved in a $6.6 \%$ native polyacrylamide gel. A 32P-labeled oligonucleotide probe $(30,000 \mathrm{cpm})$ was then added, and the reaction mixture was incubated for another 10 minutes at room temperature. For reactions involving competitive oligonucleotides, the unlabeled competitor, at 100 -fold molar excess, and the labeled probe were premixed before addition to the reaction mixture. For supershift assays, the reaction mixture minus the probe was incubated with 2 $\mu \mathrm{L}$ of specific antibodies to NF- $\mathrm{KB}$ proteins for 30 minutes at room temperature. The 32P-labeled oligonucleotide probe was then added, and incubation was continued for 15 minutes. The samples were analyzed on $6 \%$ acrylamide gels. The gels were pre-electrophoresed at $12 \mathrm{~V} / \mathrm{cm}$ for 1.5 hours at room temperature and 0.5 hours in a cold room, and the electrophoresis was continued at the same voltage for another 2 hours at room temperature. Gel contents were transferred to Whatman chromatography paper (Markson Lab Sales, Hillsboro, OR), dried, and exposed to a PhosphorImage screen (Molecular Dynamics, Sunnyvale, CA) for 3 hours.

\section{Immunohistochemistry} and alginate-encapsulate tumor cell assay

To explore whether the antitumor immunity involved the inhibition of angiogenesis, detection of vessel density in tumor tissue and angiogenesis in vivo was done as described 
previously. ${ }^{27}$ Frozen sections were used to determine vessel density with an anti-CD31 antibody. In addition, an alginate-encapsulate tumor cell assay was done. One group was treated with Lipo-cur by intravenous injection once a day for a week, and one group was treated with empty liposome. After 12 days, mice were injected intravenously with $0.1 \mathrm{~mL}$ of a $100 \mathrm{mg} / \mathrm{kg}$ fluorescein isothiocyanate (FITC)-dextran (Sigma) solution. Alginate beads were photographed after being exposed surgically and then rapidly removed 20 minutes after FITC-dextran injection. The uptake of FITC-dextran was measured as described previously. ${ }^{28}$

\section{Histopathological analysis}

Hematoxylin-eosin (HE) staining and picric acid-Sirius red dyeing were performed. Mouse lungs were fixed by perfusion with $4 \%$ paraformaldehyde-PBS before routine processing and paraffin embedding. Sections $(3 \mu \mathrm{m})$ were stained with HE for histological examination. The Ashcroft score was used for semiquantitative assessment of fibrotic changes. ${ }^{29,30}$ The severity of fibrotic changes in each histological section of the lung was assessed as the mean score of severity from observed microscopic fields. Thirty fields in each section were analyzed. After examination of the whole fields of the section, the mean of the scores from all fields was considered the fibrotic score. To prevent bias of observation, grading was done in a blinded fashion by two observers.

\section{Statistical analysis}

SPSS Statistics (IBM Corporation, Somers, NY) software, version 11.5, was used for statistical analysis. The statistical significance of results in all of the experiments was determined by Student's $t$-test and analysis of variance. Survival curves were compared by the log-rank test. The findings were regarded as significant if $P<0.05$.

\section{Results}

Here, Lipo-cur with good water solubility was developed to explore its radioprotective effects for lung tissue, and sensitizing activity to lung cancer cells, in mice models with radiation. The study showed that a systemic administration of Lipo-cur could inhibit RP and sensitize lung carcinoma to radiation.

\section{Preparation and characterization of Lipo-cur}

Liposomes have been widely used carriers for lipophilic drugs. ${ }^{31,32}$ By preparing liposomes in this study, the concentration of curcumin in aqueous phase was significantly increased.

The Lipo-cur had a DL and an EE of $5.0 \pm 0.2$ and $90.1 \pm 1.7$, respectively $(n=3)$. The liposomes were characterized by photon correlation spectroscopy and exhibited a mean particle size of $114.9 \pm 7.3 \mathrm{~nm}$. The polydispersity index was $0.15 \pm 0.04$, indicating a very narrow particle size distribution. The liposomes were negatively charged, with a zeta potential of $-2.62 \pm 0.51 \mathrm{mV}(\mathrm{n}=3)$. The particle size observed by transmission electron microscopy was consistent to that determined by particle size. The irregular surfaces of the spheres were probably ascribed to the dehydration process during sample preparation.

The appearance of curcumin aqueous solution, Lipo-cur, and curcumin ethanol solution are shown in Figure 1D. As curcumin is water-insoluble, its PBS solution was turbid. In contrast, the Lipo-cur solution was a translucent, yellow dispersion without sedimentation. The curcumin ethanol solution was clear and transparent.

\section{Detection of toxicity}

The mice treated with Lipo-cur were in particular investigated for the potential long-term toxicity. No adverse consequences were indicated in gross measures such as weight loss (Figure 2A), ruffling of fur, or life-span (Figure 2B). Furthermore, no pathologic changes of liver, kidney, lung, spleen, or brain were found by the microscopic examination (data not shown).

\section{Effect of curcumin treatment on RP from single fraction $X$-ray radiation to the thorax in mice}

Lungs were analyzed at 7, 14, 21, 28, 35, and 42 days for the onset of the pneumonitis reaction. Histopathologic changes were judged by two independent investigators in a blinded manner. These results revealed that radiation once with 14 Gy lead to an increase in acute inflammatory infiltrate in the interstitium. The mice from the control group developed pathognomonic alterations characteristic of pneumonitis, including alveolar wall thickness, interstitial edema, and interstitial and peribronchial inflammation after radiation. However, the lung tissue from the Lipo-cur-treated group only showed slight histopathologic changes during the 6 weeks (Figure 3A). The murine lung inflammation from the control group had further developed until progressive fibrosis of interstitium, while the systemic and repeated administration of Lipo-cur not only inhibited the onset of RP, but also retarded its process and sequelae (Figure 3B). The degree of 

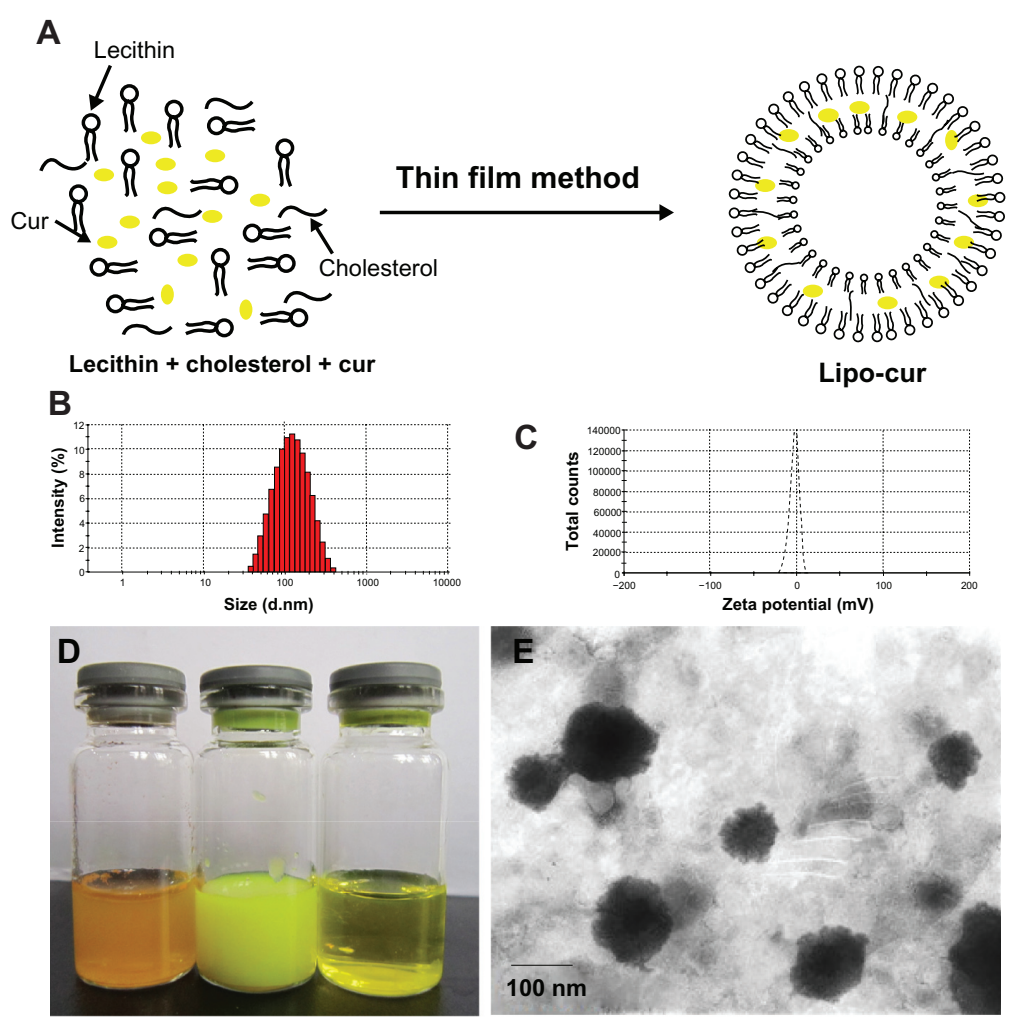

Figure I Preparation and characterization of Lipo-cur. (A) Preparation scheme of Lipo-cur. (B) Size distribution of Lipo-cur. (C) Zeta potential of Lipo-cur. (D) Photographs of curcumin phosphate-buffered solution, Lipo-cur, and curcumin ethanol solution (from left to right). (E) Transmission electron microscopy image of Lipo-cur. Abbreviations: Cur, curcumin; Lipo-cur, liposomal curcumin.

type I collagen deposition was confirmed by lung histology stained with Picric Acid-Sirius Red (Figure 4A). As anticipated, lung tissue specimens from the empty liposome group showed extensive Picric Acid-Sirius Red staining, indicating type I collagen deposition inside the alveolar wall.
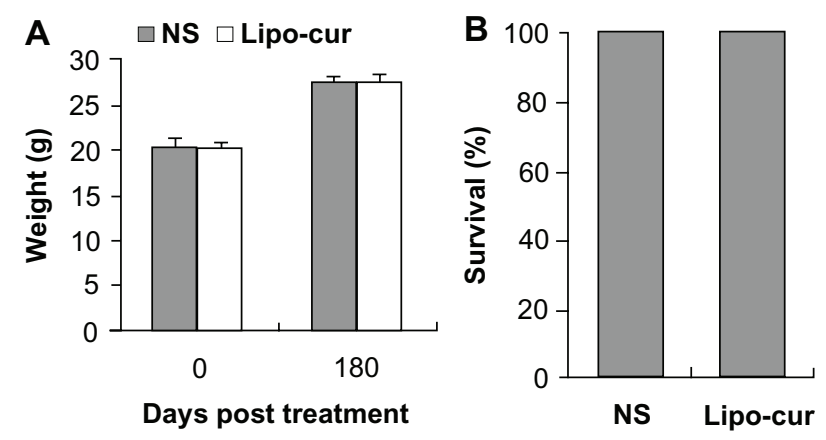

Figure 2 The effects of the treatment with Lipo-cur on body weight and life span. Normal C57BL/6] mice (7 weeks old, 20 mice per group) were treated intravenously with Lipo-cur $(5 \mathrm{mg} / \mathrm{kg}$ ), and NS was injected into each group through the tail vein. The injections were continued for 7 days, but mice were not challenged with tumor cells. Mice in each group were investigated for potential toxicity for 6 months. (A) There was no weight loss in the mice treated with Lipo-cur, compared with control groups $(P>0.05)$. The results are expressed as mean weight, and error bars represent \pm standard error of the mean. (B) There was no decrease in life span in the mice treated with Lipo-cur, compared with the control groups $(P>0.05)$. Note: Data represent percentage of survival at day 180 after the treatment. Abbreviations: Lipo-cur, liposomal curcumin; NS, normal saline.
This suggested that the degree of lung fibrosis in the control group significantly increased compared with that in the Lipocur-treated group $(P<0.01)$ (Figure 4B).

\section{Cytokine plasma levels at the onset of RP mice}

As a result of clearing apoptotic cells or as a direct response to radiation, the activation of macrophages may cause cytokine production, leading to lung injury. ${ }^{33}$ Here, the inhibitory effects of curcumin on activation of macrophages was investigated. The results showed that curcumin not only inhibited the activity of NF- $\mathrm{KB}$, but also blocked the migration of macrophages (Figure $5 \mathrm{~A}$ and $\mathrm{B}$ ). In vivo, plasma levels of both curcumin and NS group for IL-6, IL-8, TNF- $\alpha$, and TGF- $\beta$ cytokine concentration were measured at the first month of RP. The level of TGF- $\beta$ from the Lipo-cur treatment group was lower than the NS group from the first week to the fourth week. Moreover, the level of TGF- $\beta$ in the third week and fourth week was lower than that in the first week and second week in the Lipo-cur treatment group (Figure 5C). No difference of TNF- $\alpha$ and IL- 8 was observed between the NS group and Lipo-cur group after the first week, but the level of TNF- $\alpha$ and IL- 8 of the Lipo-cur group was lower than in 
A

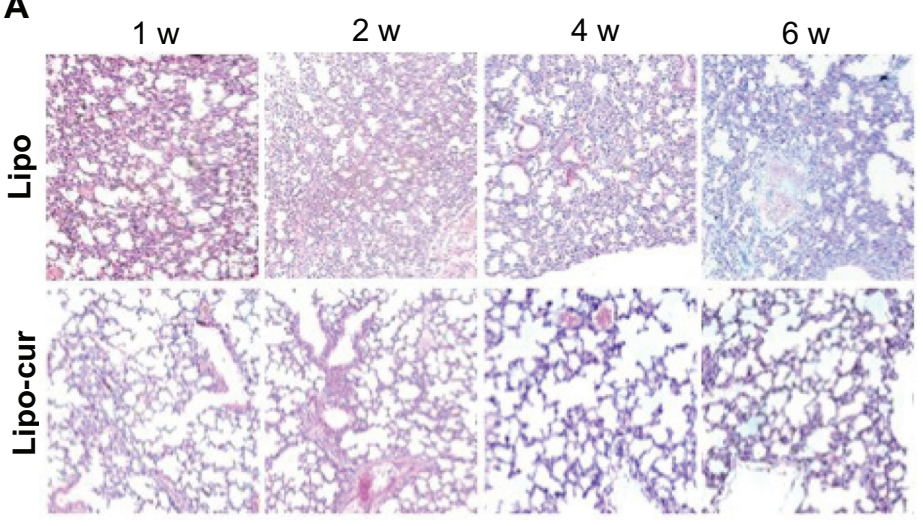

B

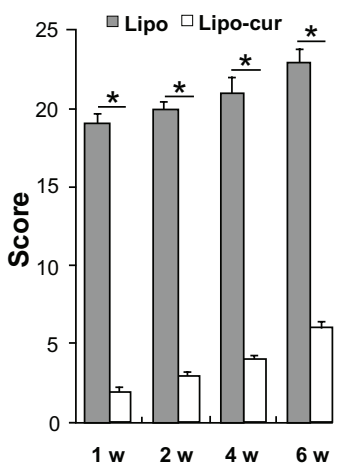

Figure 3 Lipo-cur inhibits the radiation-inducing pneumonitis in C57 mice. (A) The HE-stained images of histological sections. At weeks I, 2, 4, and 6, histological sections were taken from lungs of irradiated C57BLL/6 J and analyzed at $\times 100$ magnification. The mice treated with Lipo-cur show a significant inhibition to the radiation-inducing pneumonitis. (B) The histology scores (see material and method) for the empty Lipo group and Lipo-cur group are shown for weeks I, 2, 4, and 6 after radiation.

Notes: Data are from two representative lung sections per animal from three different animals per group. Data are mean \pm standard error of the mean; $*$ denotes $P<0.0$ I between groups.

Abbreviations: Lipo, liposome; Lipo-cur, liposomal curcumin; w, week.

the NS group after the second week (Figure 5D and E). The level of IL-6 from the Lipo-cur treatment group was lower than the NS group from the first week to the fourth week; it reached its peak at the second week and then showed a gradual downward trend (Figure 5F).

\section{Effects of curcumin and radiotherapy on tumor treatment}

It has been reported that curcumin sensitizes human colorectal cancer xenografts in nude mice to gamma-radiation by targeting NF-KB-regulated gene products. The sensitizing effects of curcumin on murine lung cancer cells were investigated in LL/2 Lewis lung carcinoma cell model. There was significant inhibition of tumor growth in mice treated with curcumin plus radiotherapy. Although the antitumor effects were also detected in mice treated with curcumin and radiotherapy separately, the data suggest that the combined treatment of curcumin and radiotherapy can elicit an enhanced antitumor effect (Figure 6A and B). The further data from terminal deoxynucleotidyl transferase dUTP nick end labeling (TUNEL) test also revealed curcumin plus radiotherapy induced significantly increased cellular apoptosis (Figure 6C and D). Therefore, the data suggest that Lipo-cur not only inhibit the process of RP, but also sensitize the antitumor effect of irradiation.

\section{Inhibition of angiogenesis}

A previous study indicates that irradiation induces endothelial cell apoptosis and resulting microvascular damage regulates tumor cell response to radiation..$^{34}$ Accumulating evidence have been documented that curcumin inhibits angiogenesis by targeting endothelial cells. ${ }^{35-37}$ In this study,

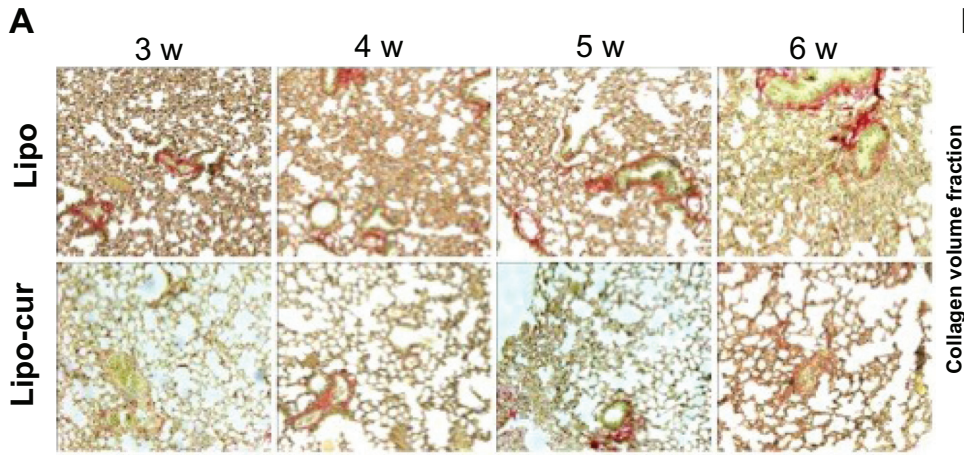

B

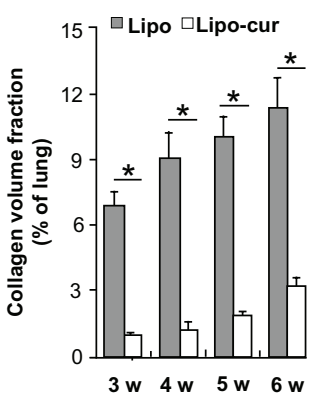

Figure 4 Lipo-cur inhibits radiation-inducing fibrosis in C57 mice. (A) Picric Acid-Sirius Red staining of lung tissue. Sections of the lung from radiated C57 mice at 3, 4, 5, and 6 weeks were analyzed for interstitial collagen content by Picric Acid-Sirius Red staining. Magnification: $\times$ I00. (B) Quantification of lung fibrosis by Sirius Red staining and subsequent semi-automated image analysis. Data are from two representative lung sections per animal from three different animals per group.

Notes: Data are mean \pm standard error of the mean; *denotes $P<0.01$ between groups.

Abbreviations: Lipo, empty liposome; Lipo-cur, liposomal curcumin; w, week. 


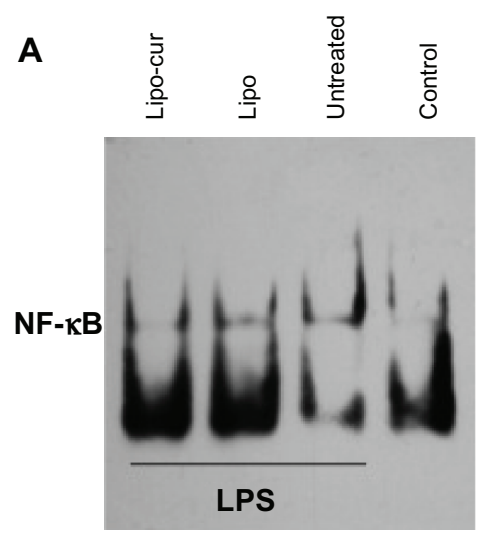

B

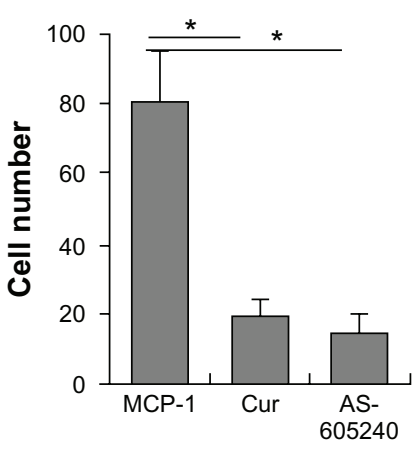

D

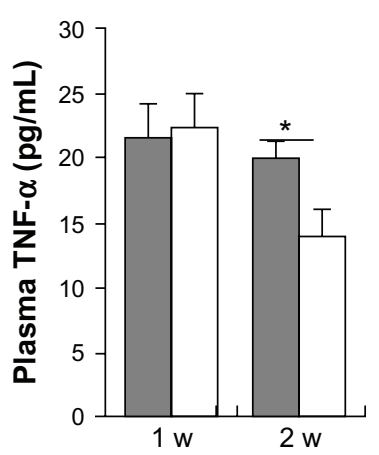

E

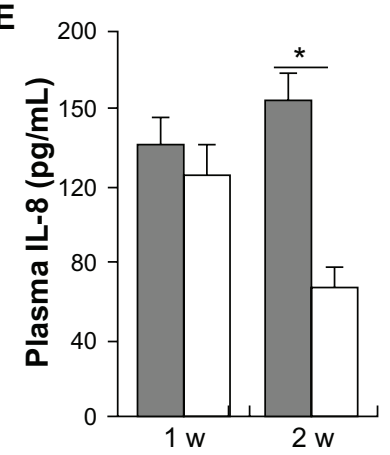

C

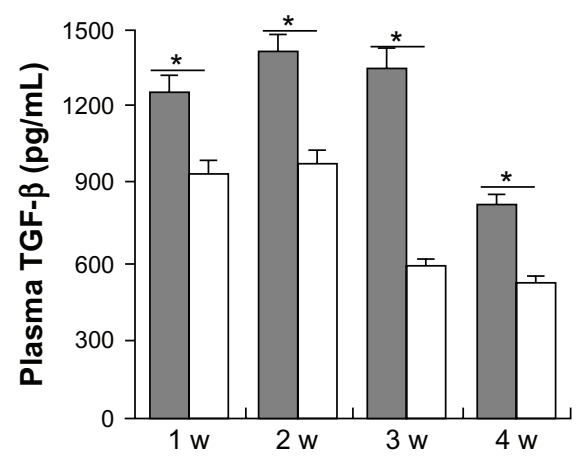

$\mathbf{F}$

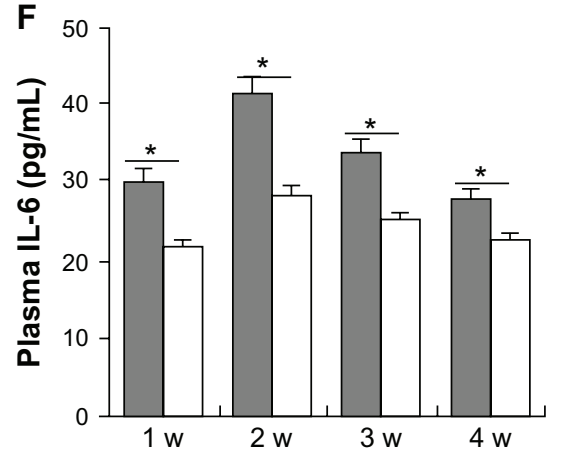

Figure 5 Lipo-cur inhibits the activation of macrophages and downregulates the serum levels of pro-inflammatory cytokines. The inhibitory effect of Curcumin on activation of macrophages was detected first. (A) Curcumin inhibited the activity of NF-KB of macrophages. (B) Curcumin blocked the migration of macrophages (MCP-I, Cur: Cur+MCP-I, AS605240: AS605240+MCP-I). Then, the serum levels of both the Lipo and Lipo-cur group for IL-6, IL-8, TNF- $\alpha$, and TGF- $\beta$ cytokine concentration were measured at the first month of RP, mice in each group were bled for serum at the end of week I, 2, 3, and 4 after being treated with Lipo or Lipo-cur. (C) The level of TGF- $\beta$ from the Lipo-cur treatment group and the Lipo group. (D) The level of TNF- $\alpha$ from the Lipo-cur treatment group and the Lipo group. (E) The level of IL-8 from the Lipocur treatment group and the Lipo group. (F) The level of IL-6 from the Lipo-cur treatment group and the Lipo group.

Notes: Data are mean \pm standard error of the mean; *denotes $P<0.05$ between groups.

Abbreviations: Cur, curcumin; IL, interleukin; Lipo, empty liposome; Lipo-cur, liposomal curcumin; MCP, monocyte chemotactic protein; NF, nuclear factor; TGF, transforming growth factor; TNF, tumor necrosis factor.

immunohistochemical staining (Figure 7A) of the tumor tissue from curcumin-treated mice with an anti-CD31 antibody showed significantly decreased microvessel density compared with that of the empty liposome group. Interestingly, the microvessels were still obviously observed in tumor tissue from single irradiation-treated mice; however, both the microvessels and cancer cells showed morphologic abnormality, suggesting the damages and disfunction of these microvessels. The combined treatment with Lipo-cur plus radiotherapy resulted in significantly decreased microvessels (Figure 7A and B). In addition, inhibition of angiogenesis could also be detected in the alginate-encapsulate tumor cell assay (Figure 7C and D). New blood vessels in alginate beads from curcumin therapic mice were apparently sparse. Besides, FITC-dextran uptake was significantly decreased from Lipo-cur-treated mice. These findings further support that curcumin effectively inhibits tumor angiogenesis; it is a possible mechanism to sensitize LL/2 Lewis lung carcinoma cells to radiotherapy.

\section{Discussion}

Drug-loaded liposomes are expected to decrease the plasma clearance rate of the drug compared with free drug, and correspondingly enhance the therapeutic efficacy. ${ }^{38}$ Therefore, developed in this work was a water-soluble Lipo-cur system.

RP is a common complication of thoracic radiotherapy, and especially occurred in patients with lung cancer. Prevention and treatment of RP not only ameliorate patients' clinical symptoms, but also improve the long-term survival quality. An optimal drug should be expected not only to prevent or treat RP, but also generate additional or synergic antitumor effects. This study suggests that the systemic administration of Lipo-cur can provide the double inhibitory effects on both RP and cancer.

The lung tissues exposed to the ionizing radiation are likely to be affected not only by the radiation results on DNA but also by the activity of pro-inflammatory cytokines, which include IL-1 $\alpha$, IL-1 $\beta$, TNF- $\alpha$, IL-6, IL-8, and TGF- $\beta$. 


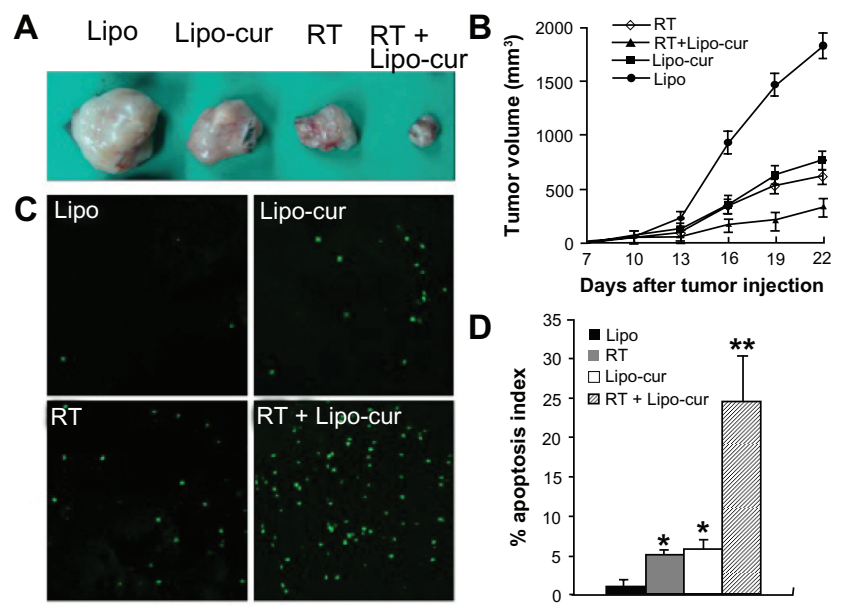

Figure 6 Lipo-cur sensitizes cancer cells to RT. (A and B) C57BL/6] mouse tumor model was established by subcutaneous injection with $5 \times 10^{5} \mathrm{LL} / 2$ cells. Mice (six mice in each group) were treated with $100 \mu \mathrm{g}$ of Lipo-cur $(\mathbf{\Delta})$ (intravenous route), RT $(\diamond)$ ), Lipo-cur (intravenous route) and RT (घ), or Lipo solution alone $(\bullet)$. Significant difference was found in tumor volume $(*$ denotes $P<0.05)$ between RTcurcumin group and those two methods alone. Points, mean $(n=8)$; bars, standard deviation. (C and D) Apoptosis of lung cancer cells was detected using TUNEL analysis. The percentage of apoptosis was determined by counting the number of apoptotic cells and dividing by the total number of cells in the field (five high power fields per slide).

Notes: The combined treatment with Lipo-cur and RT resulted in significantly increased apoptosis compared with that of other groups (*denotes $P<0.05$, **denotes $P<0.01$ ); bars, standard deviation; columns, mean.

Abbreviations: Lipo, empty liposome; Lipo-cur, liposomal curcumin; RT, radiotherapy; TUNEL, terminal deoxynucleotidyl transferase dUTP nick end labeling.

Although the target cell population and the underlying mechanism that initiates the process of RP in the lung remain unknown, it is accepted that a perpetual cascade of cytokine expression patterns are important for radiation-induced pneumonitis. ${ }^{5,39}$ The current working hypothesis suggests that complex alterations involve endothelial cells, pneumocytes, macrophages, and other resident and transient cells. ${ }^{39,40}$ Cytokines are produced not only in the normal lung tissue after radiation, but also overexpressed in tumor cells of nonsmall cell lung cancer (NSCLC) specimens. For example, IL-6 is produced by lymphocytes, macrophages, fibroblasts, endothelial cells, bronchiolar epithelium, and some tumor cells. ${ }^{41,42}$ Notably, a recent study has suggested that tumor is the major source of circulating cytokines in patients with advanced NSCLC who have received RT, ${ }^{43}$ which supports the idea that tumor cells play more important roles in the process of RP. Therefore, the prevention and treatment of RP should not only aim to cascade signaling of cytokines, but also to reduce the release of cytokines from various cells, especially cancer cells.

A previous study has shown that ionizing radiation can directly activate NF- $\kappa \mathrm{B}$ in various tumor cells and endothelial cells, ${ }^{6}$ while the activation of NF- $\kappa \mathrm{B}$ plays a central role in the regulation of multiple cellular processes such as
A

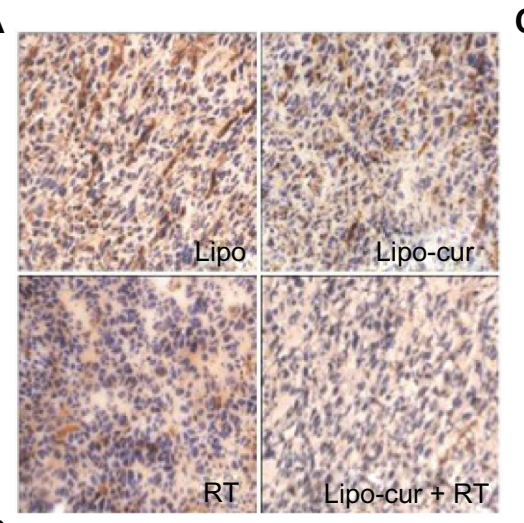

B

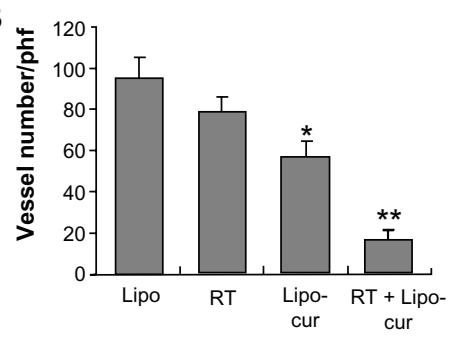

C

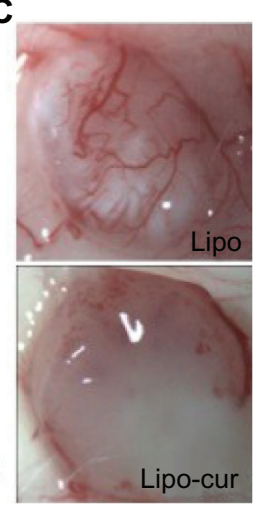

D

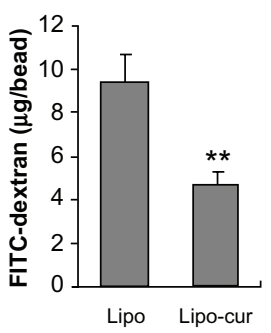

Figure $\mathbf{7}$ Inhibition of angiogenesis within tumors. (A and B) Frozen sections of tumor tissue were tested by immunohistochemical analysis of anti-CD3I antibody, and vascular density was quantified by counting the number of microvessels per high power field $(\times 400)$. Vessel density of tumor tissues from combined treatment with Lipo-cur and RT indicated a decrease compared with the phosphate-buffered saline group (five high power fields per slide). (C and D) Alginate beads containing $1 \times 10^{5} \mathrm{LL} / 2$ cells per bead were then implanted subcutaneously into the backs of mice. One group was treated with curcumin by intravenous injection once a day for I week, and one group was treated with normal saline. Beads were surgically removed 12 days later, and FITC-dextran was quantified. FITC-dextran uptake of beads from curcumin-treated mice showed a significant decrease compared with normal saline group.

Notes: *Denotes $P<0.05$; **denotes $P<0.01$; columns, mean; bars, standard deviations.

Abbreviations: FITC, fluorescein isothiocyanate; Lipo, empty liposome; Lipo-cur, liposomal curcumin; RT, radiotherapy.

inflammation, immune response, differentiation, proliferation, apoptosis, and carcinogenesis. In the process of RP, $\mathrm{NF}-\kappa \mathrm{B}$, as an important transcription factor, plays double roles both in producing and signaling of pro-inflammatory cytokines. ${ }^{7,44}$ Pro-inflammatory genes can be expressed in various cells including $\mathrm{T}$ cells, macrophages, endothelial cells, and especially tumor cells, while inhibition of NF- $\kappa \mathrm{B}$ results in a decrease of the cytokines in these cells. ${ }^{45}$ Therefore, decreasing the secretion of cytokines from these cytokine-producing cells and downregulating cytokine signaling in possible target cells are necessary to effectively inhibit the process of RP. Accumulating evidence has shown that curcumin inhibits the activity of $\mathrm{NF}-\kappa \mathrm{B}$ in various cells. ${ }^{10,45,46}$ The macrophage plays multiple roles in tissue injury and is involved in production and signal transduction of pro-inflammatory cytokines through the NF- $\kappa B$-dependent way. ${ }^{34,47,48}$ The current study showed that curcumin effectively inhibits activity of murine macrophage-like (RAW264.7) 
cells, which further proved that curcumin could mitigate RP through inhibition of the NF- $\mathrm{kB}$ pathway.

As we know, the process of RP involves a complicated signal network of cytokines and chemokines. The biological effects of TNF- $\alpha$ are achieved by activation of signaling cascades that elicit a pro-inflammatory gene expression program, leading to an increased vascular permeability, and a hallmark of the inflammatory response. ${ }^{49}$ IL-6 plays important roles in the regulation of immune response and inflammation, and can be used as a predictor of RP. ${ }^{50,51}$ IL-8 not only is a pro-inflammatory cytokine but also stimulates collagen synthesis and matrix production, even angiogenesis. ${ }^{52,53}$ TGF- $\beta$ expression in response to radiation plays an important role in postradiation lung injury, which results in collagen deposition, increased alveolar wall thickness, and endothelial damage. ${ }^{54,55}$ In this study, the systemic treatment with Lipo-cur resulted in the significant decreased sera levels of TNF- $\alpha$, IL-6, IL8, and TGF- $\beta$, which further relieved the inflammation and fibrosis of the irradiated lung. Therefore, the present study documents that curcumin can be used as a protector for RP.

Accumulating evidence has shown that curcumin sensitizes cancer cells to radiation and chemotherapy by targeting the NF- $\kappa B$ pathway. ${ }^{11,38}$ Moreover, curcumin has shown to inhibit the functions of endothelial cells by targeting the NF- $\mathrm{kB} / \mathrm{Akt}$ pathway. ${ }^{56,57}$ It is accepted worldwide that angiogenesis plays a pivotal role in tumor growth and metastases, and radiation-inducing endothelial cell apoptosis regulates tumor response to radiotherapy. ${ }^{35}$ The results of this present study further support that the systemic administration of Lipo-cur may sensitize the murine lung cancer cells to radiation by inhibiting angiogenesis and show systemic antitumor effects. Therefore, compared with other radiation protectors and therapeutic drugs of RP, such as amifostine and dexamethasone, curcumin may play another irradiation sensitizer role in further clinical application for the patients receiving thoracic radiotherapy.

A Phase I study which involved curcumin-dose escalation evaluation found no trace of curcumin at oral doses of $500-8000 \mathrm{mg} / \mathrm{d}$, and only trace amounts in a minority of patients at $10-12 \mathrm{~g}$ of curcumin intake per day. ${ }^{22}$ The therapeutic effects of curcumin are mainly limited by oral administration due to the reduced bioavailability. ${ }^{58,59} \mathrm{~A}$ variety of approaches are being pursued to overcome these limitations, which include synthesis of curcumin analogues, the use of adjuvants (eg, piperine), and the development of improved delivery platforms for the parental compound, including liposomal, nanoparticulated, and phospholipid complex formulations of curcumin. ${ }^{23}$ In this present study, the injectable Lipo-cur was prepared and a systemic administration performed. The effects of Lipo-cur were confirmed effectively; moreover, there were no observed side effects in vivo.

In summary, this study indicates that Lipo-cur may be an optimal radiation protector against RP and sensitizer for radiation therapy. The systemic administration of Lipo-cur for patients who receive thoracic radiation should be investigated in further clinical trials.

\section{Conclusion}

In this study, a water-soluble Lipo-cur system was successfully developed. The results indicate that Lipo-cur can effectively mitigate RP, reduce the fibrosis of lung, and sensitize LL/2 cells to irradiation. This study also suggests that the systemic administration of Lipo-cur is safe and deserves to be investigated for further clinical application.

\section{Acknowledgments}

This work was supported by National Major Project 2009ZX09503-005.

\section{Disclosure}

The authors report no conflicts of interest in this work.

\section{References}

1. Rodrigues G, Lock M, D’Souza D, Yu E, Van Dyk J. Prediction of radiation pneumonitis by dose-volume histogram parameters in lung cancer - a systematic review. Radiother Oncol. 2004;71:127-138.

2. Movsas B, Raffin TA, Epstein AH, Link CJ Jr. Pulmonary radiation injury. Chest. 1997;111:1061-1076.

3. Wang JY, Chen KY, Wang JT, et al. Outcome and prognostic factors for patients with non-small-cell lung cancer and severe radiation pneumonitis. Int J Radiat Oncol Biol Phys. 2002;54:735-741.

4. Schallenkamp JM, Miller RC, Brinkmann DH, Foote T, Garces YI. Incidence of radiation pneumonitis after thoracic irradiation: dosevolume correlates. Int J Radiat Oncol Biol Phys. 2007;67:410-416.

5. Rubin P, Johnston CJ, Williams JP, McDonald S, Finkelstein JN. A perpetual cascade of cytokines postirradiation leads to pulmonary fibrosis. Int J Radiat Oncol Biol Phys. 1995;33:99-109.

6. Brach MA, Hass R, Sherman ML, et al. Ionizing radiation induces expression and binding activity of the nuclear factor kappa B. J Clin Invest. 1991;88:691-695.

7. Linard C, Marquette C, Mathieu J, et al. Acute induction of inflammatory cytokine expression after gamma-irradiation in the rat: effect of an NF-kappaB inhibitor. Int J Radiat Oncol Biol Phys. 2004;58:427-434.

8. Chen MF, Keng PC, Lin PY, et al. Caffeic acid phenethyl ester decreases acute pneumonitis after irradiation in vitro and in vivo. BMC Cancer. 2005;5:158.

9. Bharti AC, Donato N, Singh S, Aggarwal BB. Curcumin (diferuloylmethane) down-regulates the constitutive activation of nuclear factor-kappa B and IkappaBalpha kinase in human multiple myeloma cells, leading to suppression of proliferation and induction of apoptosis. Blood. 2003;101:1053-1062.

10. Jobin C, Bradham CA, Russo MP, et al. Curcumin blocks cytokinemediated NF-kappa B activation and proinflammatory gene expression by inhibiting inhibitory factor I-kappa B kinase activity. J Immunol. 1999; 163:3474-3483. 
11. Kunnumakkara AB, Diagaradjane P, Guha S, et al. Curcumin sensitizes human colorectal cancer xenografts in nude mice to gamma-radiation by targeting nuclear factor-kappaB-regulated gene products. Clin Cancer Res. 2008;14:2128-2136.

12. Chendil D, Ranga RS, Meigooni D, Sathishkumar S, Ahmed MM. Curcumin confers radiosensitizing effect in prostate cancer cell line PC-3. Oncogene. 2004;23:1599-1607.

13. Khafif A, Hurst R, Kyker K, et al. Curcumin: a new radio-sensitizer of squamous cell carcinoma cells. Otolaryngol Head Neck Surg. 2005;132:317-321.

14. Wu A, Ying Z, Gomez-Pinilla F. Dietary curcumin counteracts the outcome of traumatic brain injury on oxidative stress, synaptic plasticity, and cognition. Exp Neurol. 2006;197:309-317.

15. Bharti AC, Takada Y, Aggarwal BB. Curcumin (diferuloylmethane) inhibits receptor activator of NF-kappa B ligand-induced NF-kappa B activation in osteoclast precursors and suppresses osteoclastogenesis. J Immunol. 2004;172:5940-5947.

16. Chan MM. Inhibition of tumor necrosis factor by curcumin, a phytochemical. Biochem Pharmacol. 1995;49:1551-1556.

17. Bruck R, Ashkenazi M, Weiss S, et al. Prevention of liver cirrhosis in rats by curcumin. Liver Int. 2007;27:373-383.

18. Xu YX, Pindolia KR, Janakiraman N, Chapman RA, Gautam SC. Curcumin inhibits IL1 alpha and TNF-alpha induction of AP-1 and NF-kB DNA-binding activity in bone marrow stromal cells. Hematopathol Mol Hematol. 1997;11:49-62.

19. Zeitlin P. Can curcumin cure cystic fibrosis? N Engl J Med. 2004;351: 606-608.

20. Egan ME, Pearson M, Weiner SA, et al. Curcumin, a major constituent of turmeric, corrects cystic fibrosis defects. Science. 2004;304:600-602.

21. Bisht S, Feldmann G, Soni S, et al. Polymeric nanoparticle-encapsulated curcumin ("nanocurcumin"): a novel strategy for human cancer therapy. J Nanobiotechnology. 2007;5:3.

22. Lao CD, Ruffin MT 4th, Normolle D, et al. Dose escalation of a curcuminoid formulation. BMC Complement Altern Med. 2006;6:10.

23. Bisht K, Wagner KH, Bulmer AC. Curcumin, resveratrol and flavonoids as anti-inflammatory, cyto- and DNA-protective dietary compounds. Toxicology. 2010;278(1):88-100.

24. Shahani K, Swaminathan SK, Freeman D, et al. Injectable sustained release microparticles of curcumin: a new concept for cancer chemoprevention. Cancer Res. 2010;70:4443-4452.

25. Hallahan DE, Geng L, Shyr Y. Effects of intercellular adhesion molecule 1 (ICAM-1) null mutation on radiation-induced pulmonary fibrosis and respiratory insufficiency in mice. J Natl Cancer Inst. 2002;94:733-741.

26. Maus UA, Backi M, Winter C, et al. Importance of phosphoinositide 3-kinase in the host defense against pneumococcal infection. Am J Respir Crit Care Med. 2007;175:958-966.

27. Kim YS, Ahn Y, Hong MH, et al. Curcumin attenuates inflammatory responses of TNF-alpha-stimulated human endothelial cells. J Cardiovasc Pharmacol. 2007;50:41-49.

28. Hoffmann J, Schirner M, Menrad A, Schneider MR. A highly sensitive model for quantification of in vivo tumor angiogenesis induced by alginate-encapsulated tumor cells. Cancer Res. 1997;57:3847-3851.

29. Cimolai N, Taylor GP, Mah D, Morrison BJ. Definition and application of a histopathological scoring scheme for an animal model of acute Mycoplasma pneumoniae pulmonary infection. Microbiol Immunol. 1992;36:465-478.

30. Martin RJ, Chu HW, Honour JM, Harbeck RJ. Airway inflammation and bronchial hyperresponsiveness after Mycoplasma pneumoniae infection in a murine model. Am J Respir Cell Mol Biol. 2001;24:577-582.

31. Cortesi R, Esposito E, Maietti A, Menegatti E, Nastruzzi C. Formulation study for the antitumor drug camptothecin liposomes, micellar solutions and a microemulsion. Int J Pharm. 1997;159:95-103.

32. Mohammed AR, Weston N, Coombes AG, Fitzgerald M, Perrie Y. Liposome formulation of poorly water soluble drugs: optimisation of drug loading and ESEM analysis of stability. Int J Pharm. 2004;285(1-2):23-34.
33. Zhang M, Qian J, Xing X, et al. Inhibition of the tumor necrosis factor-alpha pathway is radioprotective for the lung. Clin Cancer Res. 2008;14:1868-1876.

34. Garcia-Barros M, Paris F, Cordon-Cardo C, et al. Tumor response to radiotherapy regulated by endothelial cell apoptosis. Science. 2003;300:1155-1159.

35. Bhandarkar SS, Arbiser JL. Curcumin as an inhibitor of angiogenesis. Adv Exp Med Biol. 2007;595:185-195.

36. Mohan R, Sivak J, Ashton P, et al. Curcuminoids inhibit the angiogenic response stimulated by fibroblast growth factor-2, including expression of matrix metalloproteinase gelatinase B. J Biol Chem. 2000;275:10405-10412.

37. Kunnumakkara AB, Guha S, Krishnan S, et al. Curcumin potentiates antitumor activity of gemcitabine in an orthotopic model of pancreatic cancer through suppression of proliferation, angiogenesis, and inhibition of nuclear factor-kappaB-regulated gene products. Cancer Res. 2007;67:3853-3861.

38. $\mathrm{Lu} \mathrm{Y,} \mathrm{Wu} \mathrm{J,} \mathrm{Wu} \mathrm{J,} \mathrm{et} \mathrm{al.} \mathrm{Role} \mathrm{of} \mathrm{formulation} \mathrm{composition} \mathrm{in} \mathrm{folate}$ receptor-targeted liposomal doxorubicin delivery to acute myelogenous leukemia cells. Mol Pharm. 2007;4(5):707-712.

39. Trott KR, Herrmann T, Kasper M. Target cells in radiation pneumopathy. Int J Radiat Oncol Biol Phys. 2004;58:463-469.

40. Heinzelmann F, Jendrossek V, Lauber K, et al. Irradiation-induced pneumonitis mediated by the CD95/CD95-ligand system. JNatl Cancer Inst. 2006;98:1248-1251.

41. Kishimoto T, Akira S, Narazaki M, Taga T. Interleukin-6 family of cytokines and gp130. Blood. 1995;86:1243-1254.

42. Rube CE, Uthe D, Wilfert F, et al. The bronchiolar epithelium as a prominent source of pro-inflammatory cytokines after lung irradiation. Int J Radiat Oncol Biol Phys. 2005;61:1482-1492.

43. Rube CE, Palm J, Erren M, et al. Cytokine plasma levels: reliable predictors for radiation pneumonitis? PLoS One. 2008;3:e2898.

44. Hanada T, Yoshimura A. Regulation of cytokine signaling and inflammation. Cytokine Growth Factor Rev. 2002;13:413-421.

45. Ferreira V, Sidenius N, Tarantino N, et al. In vivo inhibition of NF-kappa $\mathrm{B}$ in T-lineage cells leads to a dramatic decrease in cell proliferation and cytokine production and to increased cell apoptosis in response to mitogenic stimuli, but not to abnormal thymopoiesis. J Immunol. 1999; $162: 6442-6450$

46. Singh S, Aggarwal BB. Activation of transcription factor NF-kappa B is suppressed by curcumin (diferuloylmethane) [corrected]. J Biol Chem. 1995;270:24995-25000.

47. Laskin DL, Sunil VR, Gardner CR, Laskin JD. Macrophages and tissue injury: agents of defense or destruction? Annu Rev Pharmacol Toxicol. 2011;51:267-288

48. Lawrence T, Bebien M, Liu GY, Nizet V, Karin M. IKKalpha limits macrophage NF-kappaB activation and contributes to the resolution of inflammation. Nature. 2005;434:1138-1143.

49. Kempe S, Kestler H, Lasar A, Wirth T. NF-kappaB controls the global pro-inflammatory response in endothelial cells: evidence for the regulation of a pro-atherogenic program. Nucleic Acids Res. 2005;33:5308-5319.

50. Arpin D, Perol D, Blay JY, et al. Early variations of circulating interleukin-6 and interleukin-10 levels during thoracic radiotherapy are predictive for radiation pneumonitis. J Clin Oncol. 2005;23:8748-8756.

51. Chen Y, Hyrien O, Williams J, et al. Interleukin (IL)-1A and IL-6: applications to the predictive diagnostic testing of radiation pneumonitis. Int J Radiat Oncol Biol Phys. 2005;62:260-266.

52. Wysoczynski M, Ratajczak MZ. Lung cancer secreted microvesicles: underappreciated modulators of microenvironment in expanding tumors. Int J Cancer. 2009;125:1595-1603.

53. Kuhlmann UC, Chwieralski CE, Reinhold D, Welte T, Buhling F. Radiation-induced matrix production of lung fibroblasts is regulated by interleukin-8. Int J Radiat Biol. 2009;85:138-143.

54. Vujaskovic Z, Marks LB, Anscher MS. The physical parameters and molecular events associated with radiation-induced lung toxicity. Semin Radiat Oncol. 2000;10:296-307. 
55. Anscher MS, Chen L, Rabbani Z, et al. Recent progress in defining mechanisms and potential targets for prevention of normal tissue injury after radiation therapy. Int $J$ Radiat Oncol Biol Phys. 2005;62:255-259.

56. Singh AK, Sidhu GS, Deepa T, Maheshwari RK. Curcumin inhibits the proliferation and cell cycle progression of human umbilical vein endothelial cell. Cancer Lett. 1996;107:109-115.

57. Bobrovnikova-Marjon EV, Marjon PL, Barbash O, Vander Jagt DL, Abcouwer SF. Expression of angiogenic factors vascular endothelial growth factor and interleukin-8/CXCL8 is highly responsive to ambient glutamine availability: role of nuclear factor-kappaB and activating protein-1. Cancer Res. 2004;64:4858-4869.
58. Lev-Ari S, Strier L, Kazanov D, et al. Celecoxib and curcumin synergistically inhibit the growth of colorectal cancer cells. Clin Cancer Res. 2005;11:6738-6744.

59. Garcea G, Jones DJ, Singh R, et al. Detection of curcumin and its metabolites in hepatic tissue and portal blood of patients following oral administration. Br J Cancer. 2004;90:1011-1015.
International Journal of Nanomedicine

\section{Publish your work in this journal}

The International Journal of Nanomedicine is an international, peerreviewed journal focusing on the application of nanotechnology in diagnostics, therapeutics, and drug delivery systems throughout the biomedical field. This journal is indexed on PubMed Central,

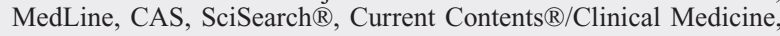

\section{Dovepress}

Journal Citation Reports/Science Edition, EMBase, Scopus and the Elsevier Bibliographic databases. The manuscript management system is completely online and includes a very quick and fair peer-review system, which is all easy to use. Visit http://www.dovepress.com/ testimonials.php to read real quotes from published authors.

Submit your manuscript here: http://www.dovepress.com/international-journal-of-nanomedicine-journal 